\title{
A Rare Case of Carcinoma of Unknown Primary in an Elderly Female: Parotid Metastases from Gastrointestinal Primary
}

\author{
Venkata Pradeep Babu Koyyala ${ }^{1}$ Sumit Goyal ${ }^{1} \quad$ Ankush Jajodia ${ }^{2} \quad$ Manish Sharma ${ }^{1}$ Manoj Gupta ${ }^{3}$ \\ BP Amrith ${ }^{1}$ Jahangir Alam¹ Rakshya Shrestha ${ }^{1}$
}

${ }^{1}$ Department of Medical Oncology, Rajiv Gandhi Cancer Institute and Research Center, New Delhi, India

${ }^{2}$ Department of Radiology, Rajiv Gandhi Cancer Institute and Research Center, New Delhi, India

${ }^{3}$ Department of Nuclear Medicine, Rajiv Gandhi Cancer Institute and Research Center, New Delhi, India

\begin{abstract}
Address for correspondence Venkata Pradeep Babu Koyyala, MD, DNB, Consultant, Medical, Oncology, Assam Cancer Care Foundation, Tezpur, 784153, Assam, India (e-mail: pradeepbabu.koyyala@ gmail.com).
\end{abstract}

Ind J Med Paediatr Oncol 2021;42:113-114.
Abstract
Keywords
- gastrointestinal tract
- parotid metastases
- unknown primary

Parotid gland is a rare site of metastasis from gastrointestinal (GI) tract primary cancer. Here, we present an interesting case report of parotid metastasis from unknown primary with probable lower GI tract as a primary site of cancer, with a normal colonoscopy and upper Gl endoscopy. This case report highlights the importance of immunohistochemistry in taking treatment decisions during dilemmatic situations.

\section{Introduction}

The most common sites of metastases from colon cancer are liver, lung, and peritoneum. Metastases to other organs are relatively rare. ${ }^{1,2}$ Metastases to the parotid gland are very rare event. The primary sites that can involve parotid gland as a site of metastases are cutaneous melanoma and squamous cell carcinoma of head and neck cancers. ${ }^{3}$ Parotid metastasis from colon cancer is extremely rare. We report an interesting case who presented with symptoms related to parotid gland enlargement and finally diagnosed as metastases from lower gastrointestinal (GI) tract, with a possible regressed primary. The primary site is confirmed after an extensive immunohistochemical evaluation.

\section{Case Report}

A 72-year-old female presented to our hospital with the complaints of swelling in the left parotid region for the last 1 month. Examination revealed enlarged parotid gland and enlarged bilateral left cervical and supraclavicular nodes. Skin and breast examination was normal. Magnetic resonance imaging of the face and neck revealed a heterogeneously enhancing mass in the deep lobe of the parotid extending to the superficial lobe with central necrosis. Nodal masses are seen in the bilateral lower, posterior cervical, left infraclavicular areas. Ultrasound-guided biopsy was done from cervical lymph node. Histology was suggestive of high-grade adenocarcinoma. Immunohistochemistry was done, which was positive for $\mathrm{CK} 20, \mathrm{CDX} 2$, and MUC2 and diffusely positive for SATB2 marker and negative for CK7 marker suggestive of primary from the lower GI (colorectal) origin. Positron emission tomography-computed tomography was done (-Fig. 1), which was suggestive of metabolically active soft tissue lesion involving the deep lobe of the parotid gland and metabolically active enlarged cervical, bilateral supraclavicular, left internal mammary, periportal, pericaval, and paraaortic lymph nodes. There was no other metabolically active disease in the body and GI tract. Colonoscopy was done, which revealed no abnormality. Upper GI endoscopy was normal and tumor markers such as CEA, CA19-9, and CA-125 were within normal limits.
DOI https://doi.org/ 10.1055/s-0041-1729733 ISSN 0971-5851
(C) 2021. Indian Society of Medical and Paediatric Oncology This is an open access article published by Thieme under the terms of the Creative Commons Attribution-NonDerivative-NonCommercial-License, permitting copying and reproduction so long as the original work is given appropriate credit. Contents may not be used for commercial purposes, or adapted, remixed, transformed or built upon. (https://creativecommons.org/licenses/by-nc-nd/4.0/). Thieme Medical and Scientific Publishers Pvt. Ltd. A-12, 2nd Floor, Sector 2, Noida-201301 UP, India 
114 A Rare Case of Carcinoma of Unknown Primary in an Elderly Female Koyyala et al.

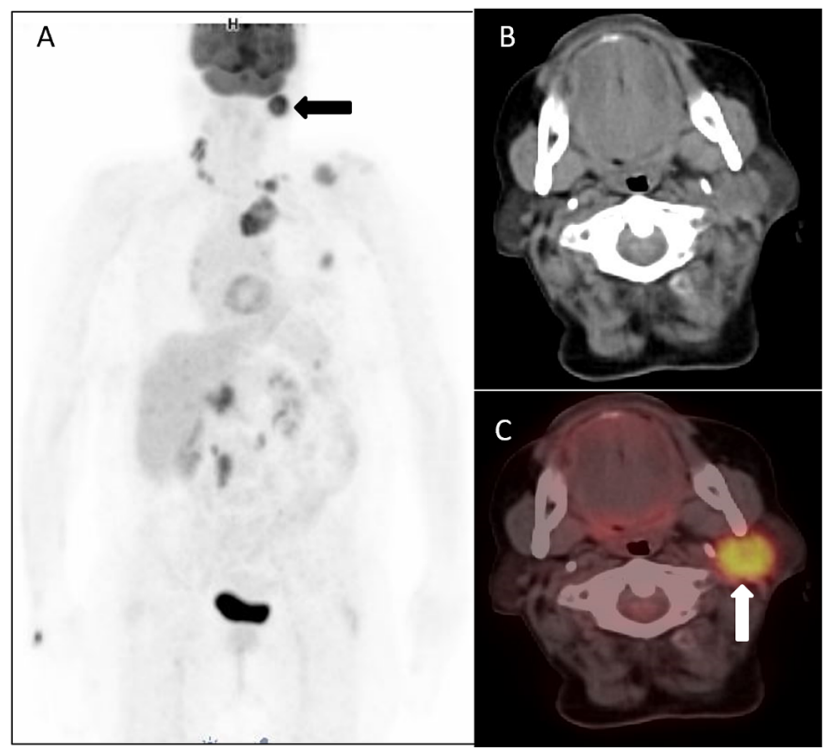

Fig. 1 18F fluorodeoxyglucose positron emission tomographycomputed tomography image: (A) maximum intensity projection, (B) axial computed tomography, and (C) fused axial, showing a metabolically active left parotid lesion (block arrows). Image (A) also shows metabolically active lymph nodes and bone lesions.

She was started on FOLFOX-based palliative chemotherapy. Post six cycles, reevaluation was suggestive of good response with decreased swelling in the parotid region with partial response radiologically according to the RECIST criteria. This case highlights the importance of immunohistochemistry in all doubtful cases and those presenting with atypical clinical signs. To our knowledge, this is only the sixth case of parotid metastases from colon cancer, but the first case to present with symptoms of parotid metastases with undetectable colonic primary. Furthermore, metastases to the parotid gland are considered as either a late or terminal event and often considered that treatment is unnecessary in the earlier literature. ${ }^{4}$ Palliative chemotherapy was offered to this patient and the patient responded to chemotherapy with symptomatic improvement.

\section{Declaration of Patient Consent}

The authors certify that they have obtained all appropriate patient consent forms. In the form, the patient(s) has/have given his/her/their consent for his/ her/their images and other clinical information to be reported in the journal. The patients understand that their names and initials will not be published and due efforts will be made to conceal their identity, but anonymity cannot be guaranteed.

\section{Financial Support and Sponsorship}

Nil.

\section{Conflicts of Interest}

There are no conflicts of interest.

\section{Acknowledgment}

This study was supported by Rajiv Gandhi Cancer Institute and Research Centre, New Delhi.

\section{References}

1 Gnepp DR, Metastatic disease to the major salivary glands. In: Ellis GL, Auclair PL, Gnepp DR, eds. Surgical Pathology of the Salivary Glands, Major Problems in Pathology Series. Philadelphia: WB Saunders; 1991 560-569

2 Abrams HL, Spiro R, Goldstein N. Metastases in carcinoma; analysis of 1000 autopsied cases. Cancer 1950;3(1):74-85

3 Yarington CT Jr. Metastatic malignant disease to the parotid gland. Laryngoscope 1981;91(4):517-519

4 Biörklund A, Eneroth CM. Management of parotid gland neoplasms. Am J Otolaryngol 1980;1(2):155-167 